\title{
Description of Non-Stationary Heat Transfer in Two-Phase Polycrystalline Metal-Ceramic Composites
}

\author{
T. SADOWSKI* AND P. GOLEWSKI
}

Lublin University of Technology, Department of Solid Mechanics, Nadbystrzycka 40, 20-618 Lublin, Poland

\begin{abstract}
The aim of the paper is to describe heat transfer in the polycrystalline ceramic composite reinforced by metallic interfaces, i.e. metal matrix composites containing ceramic grains. Example of this kind of metal matrix composites is a two-phase material composed of brittle grains of WC joined by the plastic binder Co. Micromechanical modelling of the metal matrix composites response due to heat transfer was analysed numerically with the application of the finite element analysis. This process is very complicated due to the fact that the metal matrix composites material includes: elastic grains and inter-granular metallic layers that create its really complex internal structure. The heat transfer through 2 different phases is highly nonhomogeneous and leads to visible heat flux concentrations in the metallic phase.
\end{abstract}

DOI: $10.12693 /$ APhysPolA.128.624

PACS: $44.30 .+\mathrm{v}$

\section{Introduction}

2-phase modern engineering composites are built of a wide range of components with different material properties. The variety of applied materials starts from mixtures of 2 different ceramics (e.g. $\mathrm{Al}_{2} \mathrm{O}_{3}$ and $\mathrm{ZrO}_{2}[1-5]$ ), thus creating ceramic matrices composites (CMC). Other types of 2-phase composites are metal matrix composites (MMCs) with different metallic matrixes with randomly distributed grains, e.g. Al matrix composite containing $\mathrm{SiC}$ grains [6], or Co matrix composites containing WC grains [7-13]. Other type of 2-phase composite are functionally graded materials (FGM), where grains are situated inside the matrix in order to get controlled distribution of grains creating continuous changes of composite properties in the specified direction, e.g. [14-25]. Other types of composites have layered structures, e.g. [26-28]. Up till now the composites were analysed in the macroscopic level under the influence of the mechanical or stationary thermal loading, e.g. [29].

In this paper we extend [29] to describe non-stationary heat transfer in microscopic level inside the polycrystalline ceramic composite reinforced by metallic interfaces, MMC. We will focus on the thermal response of 2-phase material composed of brittle grains WC joined by the plastic binder Co. Micromechanical modelling of the MMCs response due to heat transfer was analysed numerically with the application of the finite element analysis (FEA). This process is very complicated due to the fact that the MMC material includes: elastic grains and inter-granular metallic layers that create its really complex internal structure. The heat transfer through 2 different phases is highly non-homogeneous and leads to visible heat flux concentrations in the metallic phase.

${ }^{*}$ corresponding author; e-mail: sadowski.t@gmail.com

\section{Formulation of the problem}

Figure 1 presents an example of the 2-phase MMCs body and selected representative surface element (RSE) with details of the material internal polycrystalline structure. The body is subjected to the influence of the temperature field $T_{b}\left(x_{i}, t\right)$ on the boundary $S_{T}$. The second part of the surface boundary $S_{q}$ transfers heat inside or outside the body.

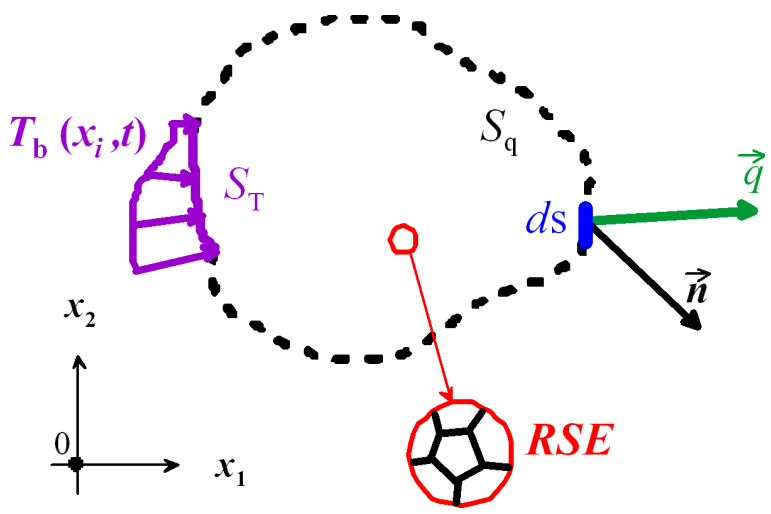

Fig. 1. Boundary condition of the problem.

The governing equation for the heat transfer through the body or the fragment of the material structure, taking into account the Fourier law and the heat flux equation has the following form:

$$
\left(k_{i j}^{\mathrm{eff}} \frac{\partial T}{\partial x_{j}}\right), i=\rho c_{v} \frac{\partial T}{\partial t},
$$

where $T\left(x_{i}, t\right)$ is the unknown temperature field, $k_{i j}^{\text {eff }}$ are components of the effective thermal conductivity tensor $k^{\text {eff }}\left(x_{i}, t\right)$ of the composite, $\rho$ is the mass density, $c_{v}$ is the specific heat of the composite and $T, j\left(x_{i}, t\right)=\partial T / \partial x_{j}$ is the temperature gradient. Equation (1) should be solved for 
- the initial boundary conditions $T_{b}\left(x_{i}, t=0\right)$ on the $S_{T}$ and $T=T_{b}\left(x_{i}, t=0\right)=\mathrm{const}$ inside of $S_{T}+S_{q}$;

- the temperature boundary conditions along the $S_{T}$, i.e. $T=T_{b}\left(x_{i}, t\right)$;

- the convective heat transfer specified on the surface $S_{q}$, i.e.

$$
\boldsymbol{q}_{i} n_{i}=h_{b} \Delta T,
$$

where $q$ is the heat flux, $h_{b}$ is the surface convective heat transfer coefficient and $\Delta T$ is the difference between the material and surrounding medium.

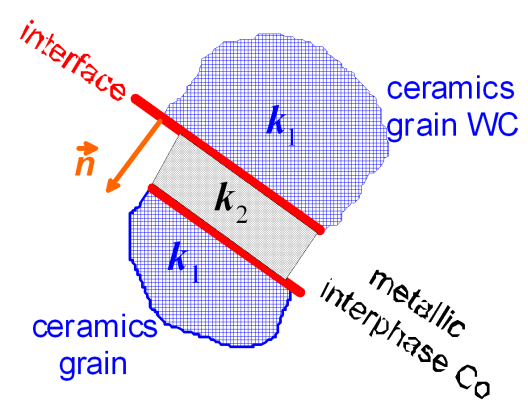

Fig. 2. Fiber-composite sample.

At the local mesolevel of the composite material structure (i.e. at the level RSE), we have the complex geometry and the local heat transfer through the joints of the 2 different phases creating the MMC, Fig. 2. The WC grains have contact through the interface with the metallic interphase Co. To simplify complexity of the modeling we assume that the interface is ideal without any impurities or microporosity. Therefore we can assume continuity of the temperature field, i.e. $T_{1}^{\text {int }}=T_{2}^{\text {int }}$. Moreover, there is no heat transfer resistance at the interface

$$
\left.k_{1}\left(\partial T_{1} / \partial n\right)\right|_{\text {int }}=\left.k_{2}\left(\partial T_{2} / \partial n\right)\right|_{\text {int }} .
$$

We assume that both phases are isotropic and homogeneous and their thermal conductivities $k_{1}$ and $k_{2}$ are constants. Then for the considered random 2-phase composite the local heat transfer through the material is described by

$$
k(T, i i)=\rho c_{v} \frac{\partial T}{\partial t} .
$$

Following [30] Eq. (4) is modified using $k_{1}$ or $k_{2}$ according to modelling heat transfer through phase 1 or 2 , using

$$
k=\left\{\begin{array}{l}
k_{1} \chi_{1}\left(x_{k}\right) \\
k_{2} \chi_{2}\left(x_{k}\right)
\end{array}\right\},
$$

where $\chi_{1}\left(x_{k}\right)$ and $\chi_{2}\left(x_{k}\right)$ are functions indicating regions of the ceramic grains -1 or the metallic interphase -2 .

\section{Numerical method and results}

Because of complexity of the problem, the solution was done with application of the finite element (FE) method with Abaqus code. Taking into account the scanning electron microscopy (SEM) photographs the following internal structure of the $\mathrm{WC} / \mathrm{Co}$ composite with different Co volume content $V^{\mathrm{Co}}$ were analysed, Fig. 3 . The RSE is subjected to the uniform thermal boundary conditions along both vertical edges. The RES is subjected to heating process from the left hand side of the unit cell from $T_{1}=293 \mathrm{~K}$ to $373 \mathrm{~K}$ within $3 \mathrm{~s}$, Fig. 4 . The temperature $T_{1}^{\prime}=293 \mathrm{~K}$ is constant.

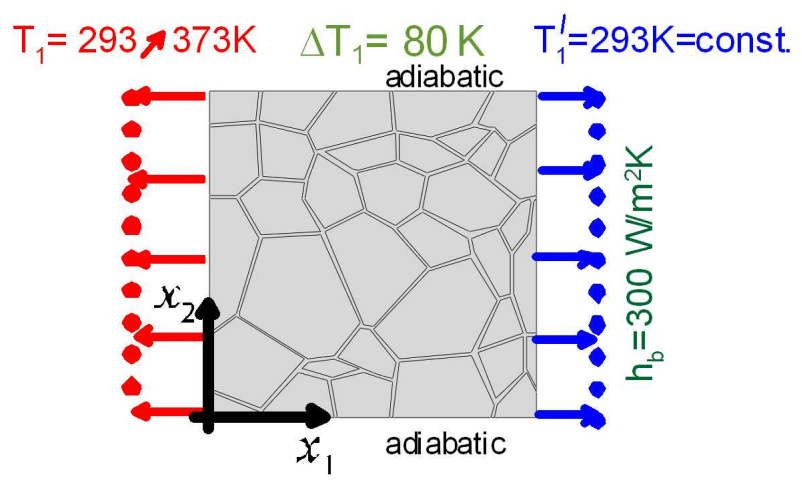

Fig. 3. RSE internal structure.

Additionally, we estimated the effective heat transfer conductivity tensor components $k^{\text {eff }}\left(x_{i}, t\right)$ along coordinate axes $x_{1}$ and $x_{2}\left(k_{11}^{\text {eff }}, k_{22}^{\text {eff }}\right)$ according to

$$
k_{i i}^{\text {eff }}=q_{i}^{\mathrm{av}} \delta_{i} / \Delta T_{i}, \quad i=1,2,
$$

where $\left\{q_{1}^{\text {av }}, q_{2}^{\text {av }}\right\}$ are components of the averaged heat flux vector $\boldsymbol{q}^{\mathrm{av}}$ for the walls of the RSE, i.e. for $x_{1}=$ 0 or $\delta_{1}$ and $x_{2}=0$ or $\delta_{2}$. In Eq. (6) there is no summation over $i$.
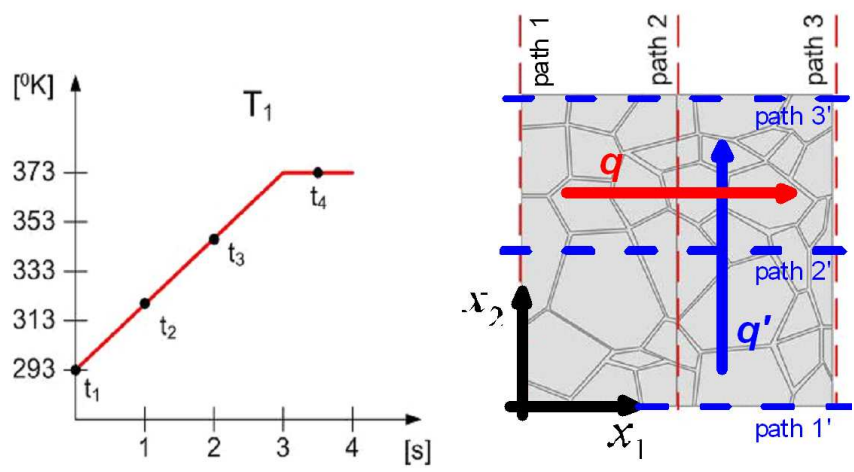

Fig. 4. Heating process of the RSE.
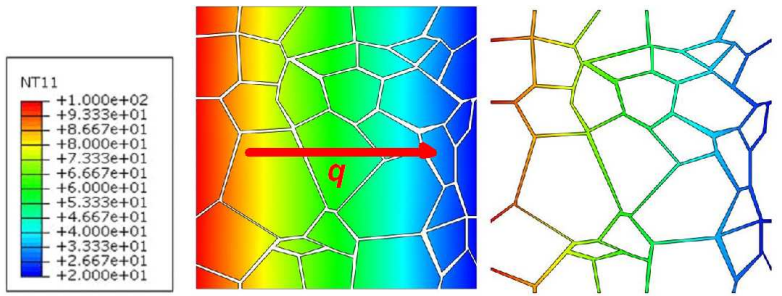

Fig. 5. Temperature distribution for $t_{4}=3.5 \mathrm{~s}$. 


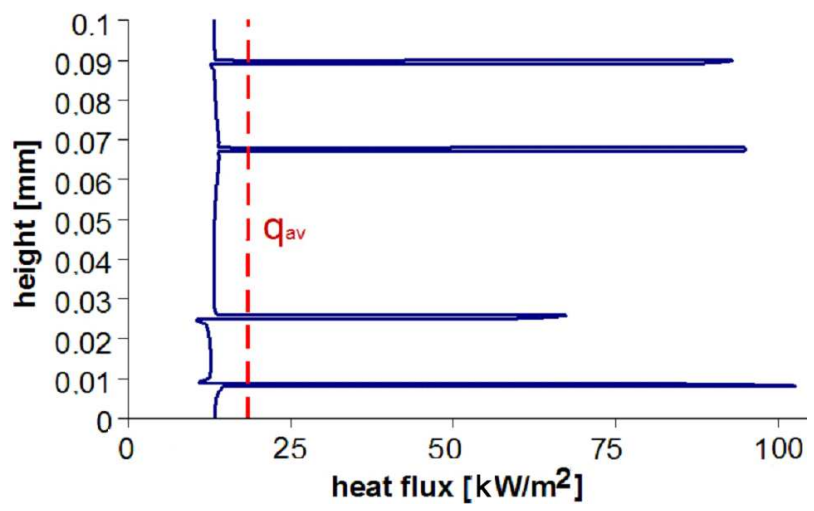

Fig. 6. Heat flux distribution in $t_{4}=3.5 \mathrm{~s}$ - path 1 - in composite with $V^{\text {Co }}=10 \%$.

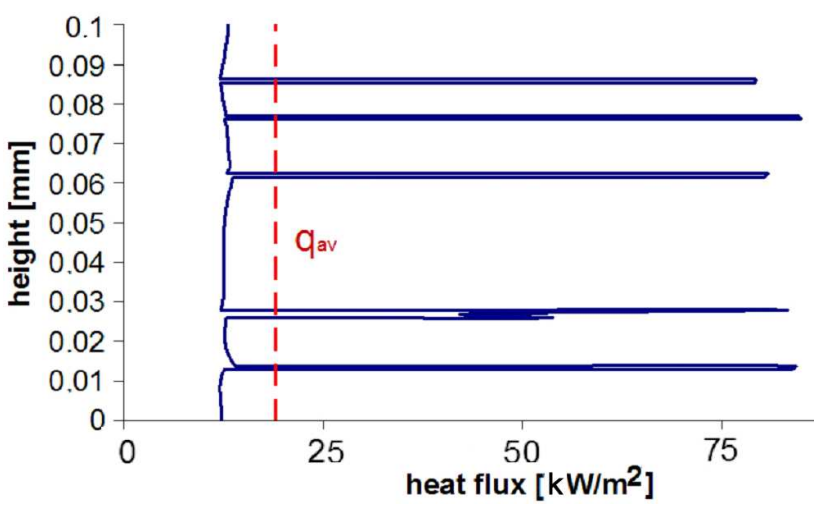

Fig. 7. As in Fig. 6, but for patch 2 .

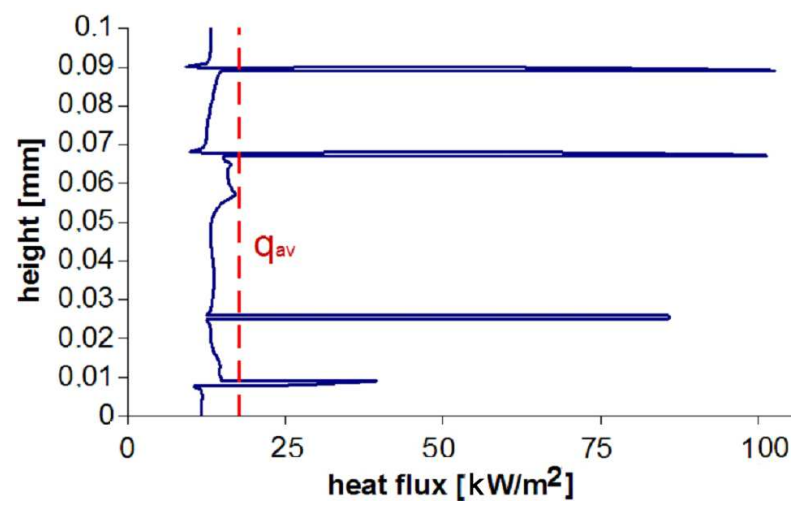

Fig. 8. As in Fig. 6, but for patch 3.
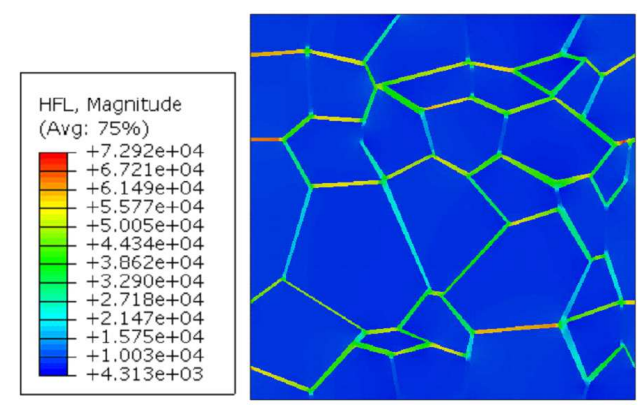

Fig. 9. Heat flux $\left[\mathrm{W} / \mathrm{m}^{2}\right]$ distribution in the whole RSE in $t_{4}=3.5 \mathrm{~s}$ within composite with $V^{\mathrm{Co}}=10 \%$.
Numerical calculations were performed for 3 selected paths, Fig. 4 in horizontal direction. The heat conductivity for $\mathrm{WC}$ was equal to $k_{1}=14.8 \mathrm{~W} / \mathrm{mK}$ and $k_{2}=100 \mathrm{~W} / \mathrm{mK}$ for Co.

In case of $V^{\mathrm{Co}}=10 \%$ the exemplary temperature distribution for the time $t_{4}=3.5 \mathrm{~s}$ is presented in Fig. 5 .

Figures 6-8 show heat flux vector $\boldsymbol{q}$ distributions along 3 selected paths (Fig. 4).

One can notice strongly non-homogeneous heat transfer, i.e. heat flux concentrations along the metallic interphase Co, Fig. 9.

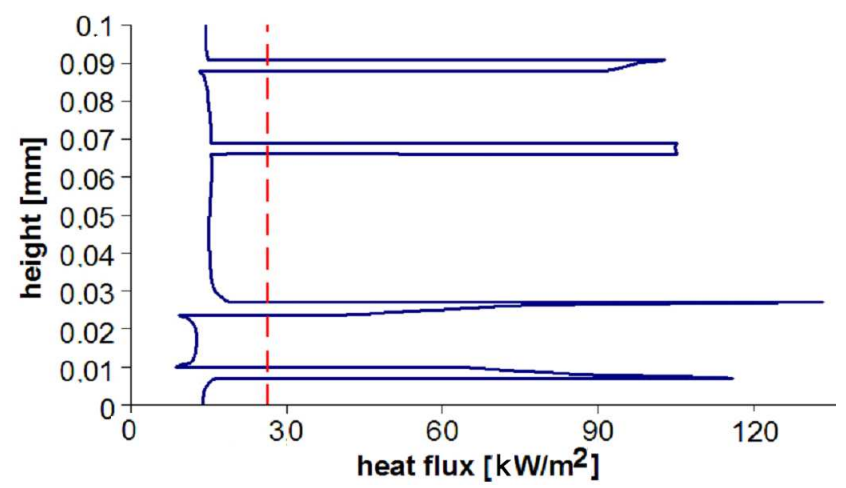

Fig. 10. Heat flux distribution in $t_{4}=3.5 \mathrm{~s}-$ path 1 - in composite with $V^{\mathrm{Co}}=24.7 \%$.

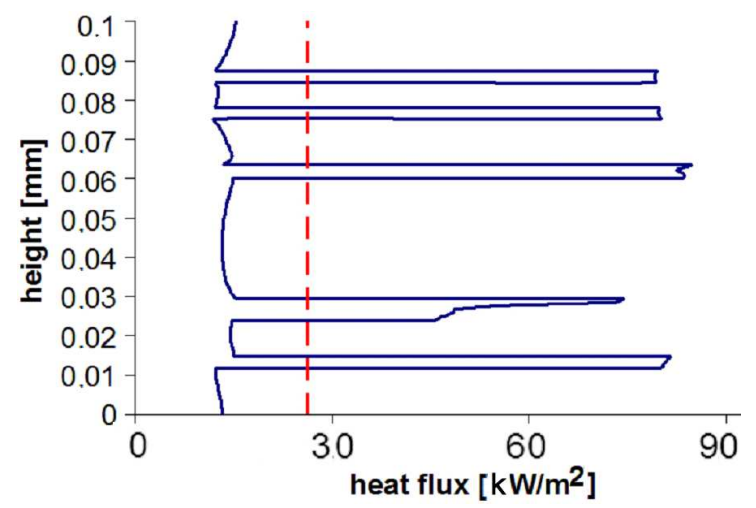

Fig. 11. As in Fig. 10, but for patch 2.

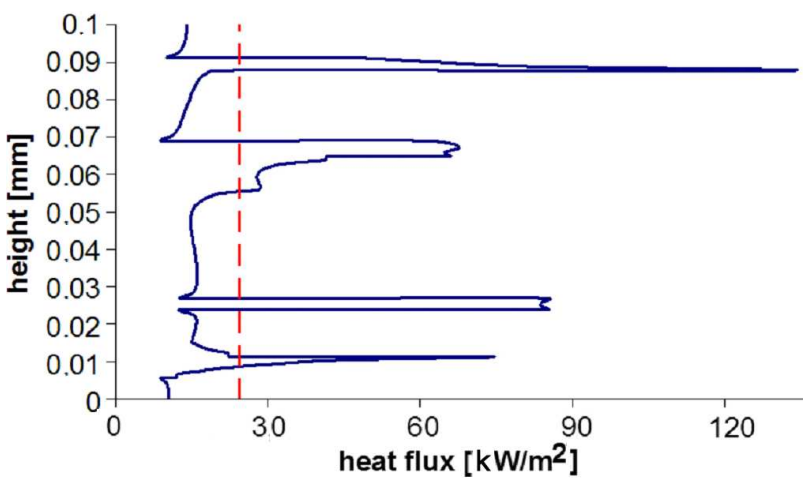

Fig. 12. As in Fig. 10, but for patch 3 . 
The comparative calculations were done for MMC with higher volume content of the Co, i.e. $V^{\mathrm{Co}}=27.4 \%$.

The temperature distribution for the time $t_{4}=3.5 \mathrm{~s}$ is almost the same as in Fig. 5. However, the heat transfer in this composite is much higher, see Figs. 10-12.

Comparing Figs. 9 and 13 it is easily noticeable that the heat flux is almost twice higher for the material with $2.7 \times$ higher volume content $V^{\mathrm{Co}}$ of the cobalt binder.

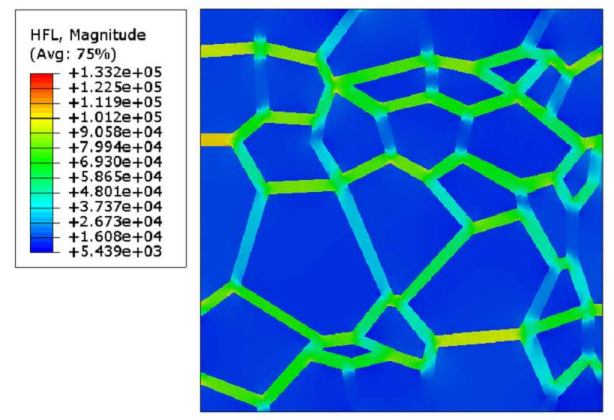

Fig. 13. Heat flux $\left[\mathrm{W} / \mathrm{m}^{2}\right]$ distribution in the whole RSE in $t_{4}=3.5 \mathrm{~s}$ within composite with $V^{\mathrm{Co}}=27.4 \%$.

Following Eq. (6) the effective heat transfer conductivities were estimated for the horizontal direction, i.e. $k_{11}^{\text {eff }}$ (Table I). One can notice that $k_{11}^{\text {eff }}$ is approximately $40 \%$ higher in the case of the composite with $V^{\mathrm{Co}}=27.4 \%$.

TABLE I

The effective heat transfer for conductivities for horizontal directions.

\begin{tabular}{c|c|c|c}
\hline \hline$k_{11}^{\text {eff }}[\mathrm{W} /(\mathrm{m} \mathrm{K})]$ & Path 1 & Path 2 & Path 3 \\
\hline $\begin{array}{c}\text { model MMC with } \\
V^{\text {Co }}=10.1 \%\end{array}$ & 23.12 & 23.93 & 22.14 \\
$\begin{array}{c}\text { model MMC with } \\
V^{\text {Co }}=27.4 \%\end{array}$ & 32.97 & 32.86 & 30.68
\end{tabular}

TABLE II

The effective heat transfer heat transfer conductivities for vertical dicertions.

\begin{tabular}{c|c|c|c}
\hline \hline$k_{22}^{\text {eff }}[\mathrm{W} /(\mathrm{m} \mathrm{K})]$ & path $1^{\prime}$ & path $2^{\prime}$ & path $3^{\prime}$ \\
\hline $\begin{array}{c}\text { model MMC with } \\
V^{\text {Co }}=10.1 \%\end{array}$ & 22.91 & 23.37 & 22.51 \\
$\begin{array}{c}\text { model MMC with } \\
V^{\text {Co }}=27.4 \%\end{array}$ & 31.80 & 33.20 & 31.28
\end{tabular}

All calculations were repeated for the similar problem, but the heat was transferred in the vertical direction heat flux vector $q^{\prime}$, see Fig. 4 . This allows for assessment of the thermal anisotropy of the analysed MMC.

According to Eq. (6) the effective heat transfer conductivities were estimated for the vertical direction, i.e. $k_{22}^{\text {eff }}$ (Table II). One can notice that $k_{22}^{\mathrm{eff}}$ is approximately $40 \%$ higher in the case of the composite with $V^{\text {Co }}=27.4 \%$.

The received results lead to the conclusion that analysed internal structure of the MMC is thermally isotropic.

\section{Concluding remarks}

Modelling of 2-phase composite materials subjected to very quick heating process is a very complex task in the case of where both phases have extremely different thermomechanical properties. Metallic binder Co has significantly higher thermal conductivity and therefore the heat transfer in the composite is mainly through metallic interphase. The concentrations of the heat fluxes particularly in the corners of the metallic binder, so called triple points, cause residual stresses due to mismatch of the mechanical properties and after cooling of the material to room temperature. If the level of the residual stresses exceeds the local strength of the interface a crack initiation mechanism in the edges of brittle grains WC can be activated. Therefore the present numerical FE model should be enriched by incorporation of this mechanisms, by introduction of the cohesive elements, e.g. [31-40].

\section{Acknowledgments}

Financial support of Structural Funds in the Operational Programme - Innovative Economy (IE OP) financed from the European Regional Development Fund - Project "Modern material technologies in aerospace industry", No. POIG.0101.02-00-015/08 is gratefully acknowledged.

\section{References}

[1] V. Birman, L.V. Byrd, Appl. Mech. Rev. 53, 147 (2000).

[2] T. Sadowski, in: Lecture Notes on Composite Materials: Current Topics and Achievements, Eds. R. de Borst, T. Sadowski, Series: Solid Mechanics and Its Application, Vol. 145, Springer, Berlin 2008, p. 99.

[3] T. Sadowski, Comput. Mater. Sci. 64, 209 (2012).

[4] T. Sadowski, L. Marsavina, Comput. Mater. Sci. 50, 1336 (2011).

[5] T. Sadowski, S. Samborski, Comput. Mater. Sci. 43, 75 (2008).

[6] D.K. Das, P.Ch. Mishra, S. Singh, S. Pattanaik, Int. J. Mech. Mater. Eng. 1, 1 (2014).

[7] T. Sadowski, S. Hardy, E. Postek, oi.org/10.1016/j.msea.2006.03.004Mater. Sci. Eng. A 424, 230 (2006).

[8] T. Sadowski, S. Hardy, E. Postek, Comput. Mater. Sci. 34, 46 (2005).

[9] E. Postek, T. Sadowski, Comp. Interf. 18, 57 (2011).

[10] T. Sadowski, E. Postek, C. Denis, Comput. Mater. Sci. 39, 230 (2007).

[11] T. Sadowski, T. Nowicki, Comput. Mater. Sci. 43, 235 (2008).

[12] H. Debski, T. Sadowski, Comput. Mater. Sci. 83, 403 (2014).

[13] F. Felten, G. Schneider, T. Sadowski, Int. J. Ref. Mater. Hard Mater. 26, 235 (2008).

[14] B. Kieback, A. Neubrand, H. Riedel, Mater. Sci. Eng. A 362, 81 (2003). 
[15] S. Suresh, A. Mortensen, Fundamentals of Functionally Graded Materials, Institute of Materials, London 1998.

[16] T. Sadowski, A. Neubrand, Int. J. Fract. 127, 135 (2004).

[17] T. Sadowski, K. Nakonieczny, Comput. Mater. Sci. 43, 171 (2008).

[18] T. Sadowski, S. Ataya, K. Nakonieczny, Comput. Mater. Sci. 45, 624 (2009).

[19] T. Sadowski, M. Boniecki, Z. Librant, K. Nakonieczny, Int. J. Heat Mass Transfer 50, 4461 (2007).

[20] K. Nakonieczny, T. Sadowski, Comput. Mater. Sci. 44, 1307 (2009).

[21] I. Ivanov, T. Sadowski, D. Pietras, Eur. Phys. J. Spec. Topics 222, 1587 (2013).

[22] M. Birsan, H. Altenbach, T. Sadowski, V. Eremeyev, D. Pietras, Comp. Part B 43, 1315 (2012).

[23] V. Petrova, T. Sadowski, Meccanica 49, 2603 (2014).

[24] J. Sladek, V. Sladek, Ch. Zhang, oi.org/10.1016/j.commatsci.2004.09.011 Comput. Mater. Sci. 32, 532 (2005).

[25] S.M. Hosseini, M.H. Abolbashari, Heat Transf. Eng. 33, 261 (2012).

[26] T. Sadowski, P. Golewski, Comput. Mater. Sci. 50 1326 (2011).

[27] T. Sadowski, P. Golewski, Comput. Mater. Sci. 52, 293 (2012).
[28] T. Sadowski, P. Golewski, Comput. Mater. Sci. 64, 285 (2012)

[29] T. Sadowski, P. Golewski, Mat.-Wiss. U. Werkstofftech. 44, 497 (2013).

[30] M. Jiang, I. Jasiuk, M. Ostoya-Starzewski, Comput. Mater. Sci. 25, 329 (2002).

[31] T. Sadowski, M. Knec, P. Golewski, Comp. Struct. 112, 66 (2014).

[32] T. Sadowski, P. Golewski, E. Zarzeka-Raczkowska, Comput. Mater. Sci. 50, 1256 (2011).

[33] T. Sadowski, M. Knec, P. Golewski, Int. J. Adhesion Adhesives 30, 338 (2010).

[34] V. Burlayenko, T. Sadowski, Comput. Mater. Sci. 45, 658 (2009).

[35] V. Burlayenko, T. Sadowski, Comput. Struct. 92 , 2890 (2010)

[36] L. Marsavina, T. Sadowski, Comput. Mater. Sci. 44, 941 (2009)

[37] L. Marsavina, T. Sadowski, Comput. Mater. Sci. 45, 693 (2009).

[38] L. Marsavina, T. Sadowski, Int. J. Frac. 145, 237 (2007).

[39] T. Sadowski, L. Marsavina, N. Peride, E.-M. Craciun, Comput. Mater. Sci. 46, 687 (2009).

[40] V. Burlayenko, T. Sadowski, Meccanica 49, 2617 (2014). 